\title{
BONE REGENERATION IN BILATERAL MANDIBULAR THIRD MOLAR TRANS-ALVEOLAR EXTRACTION SOCKETS WITH PRF V/S PRF INFUSED WITH METRONIDAZOLE- A COMPARATIVE STUDY
}

\author{
Tripthi P. Shetty1, Lubna Kharbari², S. Girish Rao ${ }^{3}$, Prakyath Malli ${ }^{4}$, Preethi Bhat ${ }^{5}$, Ashish Rai ${ }^{6}$, Arvind Karikal $^{7}$
}

${ }^{1}$ Reader, Department of Oral and Maxillofacial Surgery, A. B. Shetty Memorial Institute of Dental Sciences, NITTE University, Mangalore, Karnataka, India.

2Private Practitioner, Department of Oral and Maxillofacial Surgery, Dental Design Concepts, Mumbai, Maharashtra, India. 3Private Practitioner, Department of Oral and Maxillofacial Surgery, Mukha Facial Surgery and Dental Implant Centre, Bangalore, Karnataka, India.

${ }^{4}$ Senior Lecturer, Department of Prosthodontics, Yenepoya Dental College, Yenepoya University, Mangalore, Karnataka, India.

${ }^{5}$ Reader, Department of Oral and Maxillofacial Surgery, Sri Siddhartha Dental College, Tumkur, Karnataka, India.

${ }^{6}$ Reader, Department of Oral and Maxillofacial Surgery, A. B. Shetty Memorial Institute of Dental Sciences, NITTE University,

Mangalore, Karnataka, India.

7Professor, Department of Oral and Maxillofacial Surgery, A. B. Shetty Memorial Institute of Dental Sciences, NITTE University, Mangalore, Karnataka, India.

\section{ABSTRACT}

\section{BACKGROUND}

Platelet Rich Fibrin has stood the test of time as an excellent augmenter of bone regeneration. It is not only cost effective and easy to produce, it also releases the much-needed cytokine cascade that promotes both soft tissue healing and bone regeneration. It is however, of utmost importance to establish other potentials of this widely used autologous agent to accelerate bone regeneration. We wanted to explore if addition of an antibiotic to PRF to improves its inherent qualities. We wanted to assess radiographically the changes in bone regeneration rate and soft tissue healing between bilateral mandibular third molar trans-alveolar extraction sockets placed with platelet-rich fibrin (PRF) alone as compared to platelet rich fibrin (PRF) gel infused with Metronidazole.

\section{METHODS}

Fifty patients undergoing bilateral mandibular third molar extractions were included in the study. PRF was inserted into the extraction socket on one side (Group A) and PRF gel infused with Metronidazole into the socket on the contra-lateral side (Group B). The soft tissue healing of the surgical sites after one week and bone regeneration rates of both the groups was assessed radiographically at 1 week, 1 month, 2 months, 3 months and 6 months and compared statistically.

\section{RESULTS}

The study was done between May 2010 and January 2012 on 50 patients with 20 women (30\%) and 30 men (70\%) with a mean age of 25 years. The healing of soft tissues was considerably better in Group B. The bone regeneration was also significantly higher in Group B than Group A at each of the follow-up intervals.

\section{CONCLUSIONS}

Platelet rich fibrin gel with Metronidazole could significantly increase the amount of new bone formation in comparison to that of PRF alone. Also, soft tissue healing was more satisfactory and predictive in those receiving PRF gel with Metronidazole.

\section{KEY WORDS}

Bone Regeneration, Soft Tissue Healing, PRF, PRF Gel with Metronidazole

HOW TO CITE THIS ARTICLE: Shetty TP, Kharbari L, Rao SG, et al. Bone regeneration in bilateral mandibular third molar transalveolar extraction sockets with PRF v/s PRF infused with metronidazole- a comparative study. J. Evolution Med. Dent. Sci. 2019;8(26):2069-2075, DOI: 10.14260/jemds/2019/456

\section{BACKGROUND}

Healing is a complex cascading process involving three key elements namely scaffolds (collagen, bone minerals), signalling molecules (growth factors) and cells (osteoclasts, osteoblasts, fibroblasts). The greatest challenge in clinical research today is to promote ideal healing with formation of viable and healthy tissue be it bone or soft tissue. Indeed,

'Financial or Other Competing Interest': None.

Submission 12-04-2019, Peer Review 16-06-2019,

Acceptance 24-06-2019, Published 01-07-2019.

Corresponding Author:

Dr. Tripthi P. Shetty,

Department of Oral and Maxillofacial Surgery,

$6^{\text {th }}$ Floor, A. B. Shetty Memorial Institute of Dental Sciences,

Derlakatte, Mangalore-575004, Karnataka, India.

E-mail: tripthi12@gmail.com

DOI: $10.14260 /$ jemds $/ 2019 / 456$

\section{(c) (i) $(5)$}

after each intervention, surgeons must face complex tissue remodelling phenomena and the consequences of healing and tissue survival and hence are constantly looking for an edge that jump starts the healing process to maximize predictability as well as the volume of bone regenerated. ${ }^{1}$ Hence came into existence the concept of Platelet Rich Fibrin (PRF) as a workhorse for local bone augmentation.

The disadvantages of donor site morbidity, age dependent bioactivity and controversies as well as concerns about disease transmission from autografts and allografts has pushed clinicians towards opting for more promising autologous material such as Platelet Rich Fibrin (PRF) for more predictive results. ${ }^{2}$ In France, the development of platelet concentrate entities in the form of a novel biomaterial Platelet Rich Fibrin (PRF) provided an autologous cicatricial material that could be used not only for grafting but also as a medium for drug delivery. 
Platelets play a central role in hemostasis and healing processes. Platelet activation cascades the coagulation mechanism and hence supports haemostasis and healing. The release of more than 35 cytokines and growth factors with platelet degranulation and activation contributes to its regenerative properties aiding healing and bone matrix initiation. $^{3}$ Active substances such as serotonin, catecholamines, von Willebrand factor, proaccelerin, osteonectin, and antimicrobial proteins released, all of which stimulate cell migration and proliferation within the fibrin matrix, launching the first stages of healing.4,5 Markedly increased platelet counts PRF therefore acts as a biological connector between the different elements of healing and as a matrix which favours neo-angiogenesis, the capture of stem cells and migration of osteo progenitor cells. It also helps in postoperative protection of surgical site and accelerates remodelling and integration of the bone. 6 The use of Metronidazole with Platelet Rich Fibrin as a flushing agent has been pioneered in the recent days by Simonipieri. ${ }^{7}$ It is a cost-effective drug that works well against pathogenic anaerobic bacteria, favourable pharmacokinetic and pharmacodynamic properties, and minor adverse effects: hence the choice of antibiotic for the anaerobic microorganisms pre-dominating the oral cavity. The Metronidazole is said to attribute to not only sterile PRF gel but also inhibits infection in initial stages of bone regeneration.

PRF has been successfully, over the years used augmentation of bone regeneration following tooth extractions, cyst enucleations or any other minor surgical bony procedures owing to its ability to produce significant acceleration of bone formation. Presently there is a need to develop autogenous materials which can augment and accelerate the healing process and minimize the risks involved with alloplastic and donor materials. PRF, in the form of a gel, can be used in conjunction with antibiotics, offering multitudes of benefit including accelerated wound healing, bone formation and maturation, graft stabilization, wound closure and haemostasis, and improving the handling properties of graft materials. ${ }^{7}$ This study aims to evaluate the augmented potency of PRF gel infused with the antibiotic agent (Metronidazole) in bone regeneration and soft tissue healing if any in comparison of PRF gel alone.

\section{METHODS}

Fifty patients visiting the department of oral and maxillofacial surgery at D.A.P.M.R.V. Dental College and Hospital requiring surgical extraction of both the lower third molars were included in the study of whom 20 were women and 30 men with a mean age of 25 years.

\section{Inclusion Criteria}

- $\quad$ Both male and female patients.

- Patients between 18-35 years of age.

- Patient indicated for trans-alveolar extraction of bilateral mandibular third molar.

- Patient with a blood concentration of platelets within the normal range (1.5 -3.5 lakh cells/cubic $\mathrm{cm}$ ).

\section{Exclusion Criteria}

- Uncontrolled systemic conditions/ diseases or psychological problems that prevent therapy or longterm follow-up.
- Radiation therapy/ Chemotherapy in the12 months before the proposed therapy

- Presence of any local infection

- A smoker.

- An unwillingness to commit to a long-term post-therapy follow-up.

A total of fifty subjects satisfying the above criteria requiring trans-alveolar extraction of bilateral mandibular third molars were selected for this prospective randomized clinical trial after obtaining informed consent. Following the aseptic surgical removal of both the mandibular third molars of an individual patient in a single sitting, one socket was randomly selected to be placed under Group A receiving only the PRF and the other socket by default was chosen under Group B to receive PRF gel Infused with Metronidazole thereby eliminating any bias.

The patients were informed of the study and their permission was sought for their participation in this study which was given clearance by the ethical committee.

\section{Overview of PRF Preparation}

PRF preparation was first developed in France by Choukroun et $\mathrm{al}^{2}$ for specific use in oral and maxillofacial surgery. This technique requires neither anticoagulant nor bovine thrombin (nor any other gelling agent). It is simply centrifuged blood without any addition. $10 \mathrm{ml}$ blood from the patient is taken without anticoagulant in test tubes which are immediately centrifuged at $2700 \mathrm{rpm}$ for 12 minutes $^{3}$. The absence of an anticoagulant implies the activation in a few minutes of most platelets of the blood sample in contact with the tube walls and the release of the coagulation cascades. Fibrinogen is initially concentrated in the high part of the tube, before the circulating thrombin transforms it into fibrin. ${ }^{3}$

\section{This results in-}

- First layer of a cellular PPP.

- Second layer of PRF clot.

- Bottom layer of RBC.

The second layer (PRF) is collected and divided into two parts into two neatly incubated test tubes. One test tube with PRF will be used for group A. To the other test tube, for every $1 \mathrm{ml}$ of PRF $1 \mathrm{ml}$ of $0.5 \%$ Metronidazole infusion fluid and $0.5 \mathrm{ml}$ of Calcium Gluconate is added for formation and standardization of PRF gel infused with Metronidazole.

PRF preparation is a highly technique sensitive procedure. The only way to achieve a surgically feasible PRF is quick handling. The longer it takes for blood collection and centrifugation greater chances of failure: The fibrin will polymerize in a diffuse way in the tube and only a small blood clot without consistency will be obtained. ${ }^{1}$

\section{Surgical Technique}

Following the aseptic trans-alveolar extraction of mandibular bilateral third molars on individual patients one socket was randomly selected to be placed under Group A receiving only the PRF $(n=50)$. The other socket by default was chosen under Group B to receive PRF gel Infused with Metronidazole $(n=50)$.Closure of the socket was done using non resorbable sutures. Only analgesics were prescribed postoperatively. 


\section{Diagnostic Record for Study}

- Radiovisuographs.

- Intra-oral Periapical Radiographs.

- Ortho-Pantomographs.

The radiographic diagnostic records are to be obtained pre and post-operatively. Regular follow up at 1st postoperative day, at $1^{\text {st }}$ month post-operative and at two, three and six months post-operatively was done for both Group A and Group B subjects. Bone formation was measured using serial radiographs at every above follow-up and data recorded. Bone regeneration seen in the Group A was compared to bone regeneration in Group $\mathrm{B}$ with the radiographs taken at same intervals, to estimate the difference in bone regeneration if any [Figure 1a-1f, 2a-2f].

\section{Radiographic Analysis}

The bone regeneration analysis using serial radiographs were done using the technique described by Matteo Chiapasco et al. ${ }^{8}$ Post extraction socket bone filling was calculated using successive radiographs taken at the mentioned follow-up intervals and converted into Radio Visio Graphs (RVG) which were analysed on Corel Draw software. The radiographs were converted to grayscale tonalities of 256 using Corel Photopaint Software. An investigator blinded to the study marks the size of the bony defect post extraction in the software. The area marked was converted into a histogram which gave the number of pixels in the residual cavity. ${ }^{8}$

The number of pixels in the residual bony defect immediate post-operative was calculated and was used as baseline at $100 \%$. The reducing number of pixels at the same site in the series of follow up radiographs represented bone formation with time. Hence percentile of bone formed eventually was assessed.

\section{Soft Tissue Assessment}

Soft tissue healing of both Group A and Group B sites were assessed simultaneously at $1^{\text {st }}$ week post operatively. Parameters assessed were-

- Erythema.

- Pain.

- Postoperative Swelling.

- Pus Formation.

- Wound Dehiscence.

Observations were recorded as: absent (0), mild (1), moderate (2) and severe (3).

\section{Statistical Analysis/Statistical Technique Used \\ Paired T test.}

\section{Null Hypothesis}

There is no significant difference in the mean no. of pixels between the two groups i.e. $\mu_{1}=\mu_{2}$

\section{Alternate Hypothesis \\ There is a significant difference in the mean no. of pixels between the two groups i.e. $\mu_{1} \neq \mu_{2}$}

\section{Decision Criterion}

The null hypothesis is rejected if the p-value is less than 0.05 . Else the null hypothesis is accepted.

\section{RESULTS}

\section{Bone Regeneration Analysis}

The number of pixels at immediate post-operative, $1^{\text {st }}$ week post-operative and at 2 months, 3 months and 6 months postoperative of both the groups were statistically compared at the same time intervals.

Paired T test was used for analysis of tabulations with regard to bone regeneration in group A and group B. The results showed significant increase in bone regeneration in group $B$ sockets which received PRF gel infused with Metronidazole in comparison to group A sockets receiving only PRF-

- $\quad$ At Post-Op time interval, the mean no. of pixels is found to be higher in group B than that of group A; however, it is not statistically significant $(\mathrm{P}>0.05)$.

- $\quad$ Lower mean pixels are recorded in group B compared to the group A at 1 week post-op time interval, and the difference is marginally statistically significant $(\mathrm{P}<0.05)$.

- The difference in mean no. of pixels of group $B$ and group $A$ is extremely statistically significant $(\mathrm{P}<0.05)$ at 2 months post-op time interval. Lower mean no. of pixels is in group B than group $\mathrm{A}$.

- The difference in mean no. of pixels between group B and group $A$ is extremely statistically significant $(\mathrm{P}<0.05)$ at 3 months post-op time interval. Lower mean no. of pixels is recorded in test group than the control group.

- The difference in mean no. of pixels between group B and group $A$ is extremely statistically significant $(\mathrm{P}<0.05)$ at 6 months post-op time interval. Lower mean no. of pixels is recorded in group B compared to the group A. [Table 1, 2]

\section{Soft Tissue Healing Analysis}

The crux of analysis of soft tissue healing is dependent on the fact that no antibiotic was prescribed to either group of patients following the procedure. Hence healing and local infection control in Group B better than in Group A can be attributed to the effects of the Metronidazole incorporated in the PRF gel. [Table 3, 4]

These readings hence tabulated using a $\mathrm{T}$ test were statistically significant ( $p$ value $<0.05$ ). [Table 5]

\begin{tabular}{|c|c|c|c|c|c|c|c|}
\hline $\begin{array}{c}\text { Time } \\
\text { Interval }\end{array}$ & Group & n & Mean & $\begin{array}{l}\text { Std. } \\
\text { Dev. }\end{array}$ & $\begin{array}{c}\text { Mean } \\
\text { difference }\end{array}$ & $\mathbf{t}$ & p-Value \\
\hline \multirow{2}{*}{ Post-0p } & Group A & 50 & 20685.02 & 9264.96 & \multirow{2}{*}{\begin{tabular}{|l|l}
6 & -1051.320 \\
1 &
\end{tabular}} & \multirow{2}{*}{-1.464} & \multirow{2}{*}{0.1464} \\
\hline & Group B & 50 & 21736.34 & 7749.21 & & & \\
\hline \multirow{2}{*}{$\begin{array}{l}1 \text { Week } \\
\text { Post-Op }\end{array}$} & Group A & 50 & 15149.56 & 7044.42 & \multirow{2}{*}{1452.460} & \multirow{2}{*}{1.990} & \multirow{2}{*}{$0.0494^{*}$} \\
\hline & Group B & 50 & 13697.10 & 4793.22 & & & \\
\hline \multirow{2}{*}{$\begin{array}{l}2 \text { Months } \\
\text { Post-Op }\end{array}$} & Group A & 50 & 9719.18 & 4366.39 & \multirow{2}{*}{2175.423} & \multirow{2}{*}{4.402} & \multirow{2}{*}{0.000027} \\
\hline & \begin{tabular}{|l|} 
Group B \\
\end{tabular} & 50 & \begin{tabular}{|l|}
7543.76 \\
\end{tabular} & 2617.71 & & & \\
\hline \multirow{2}{*}{$\begin{array}{l}\text { 3 Months } \\
\text { Post-Op }\end{array}$} & \begin{tabular}{|l} 
Group A \\
\end{tabular} & 50 & \begin{tabular}{|l|}
7027.12 \\
\end{tabular} & 3125.22 & \multirow{2}{*}{2692.960} & \multirow{2}{*}{7.569} & \multirow{2}{*}{$<0.0001^{*}$} \\
\hline & Group B & 50 & 4334.16 & 1854.10 & & & \\
\hline \multirow{2}{*}{$\begin{array}{l}6 \text { Months } \\
\text { Post-Op }\end{array}$} & Group A & 50 & 633.40 & 386.16 & \multirow{2}{*}{437.280} & \multirow{2}{*}{8.621} & \multirow{2}{*}{$<0.0001^{*}$} \\
\hline & Group B & 50 & 196.12 & 143.11 & & & \\
\hline \multicolumn{8}{|c|}{$\begin{array}{c}\text { Table 1. Paired T Test for Comparison of Bone Regeneration } \\
\text { Between Group A and Group B }\end{array}$} \\
\hline & & & & & & & \\
\hline
\end{tabular}




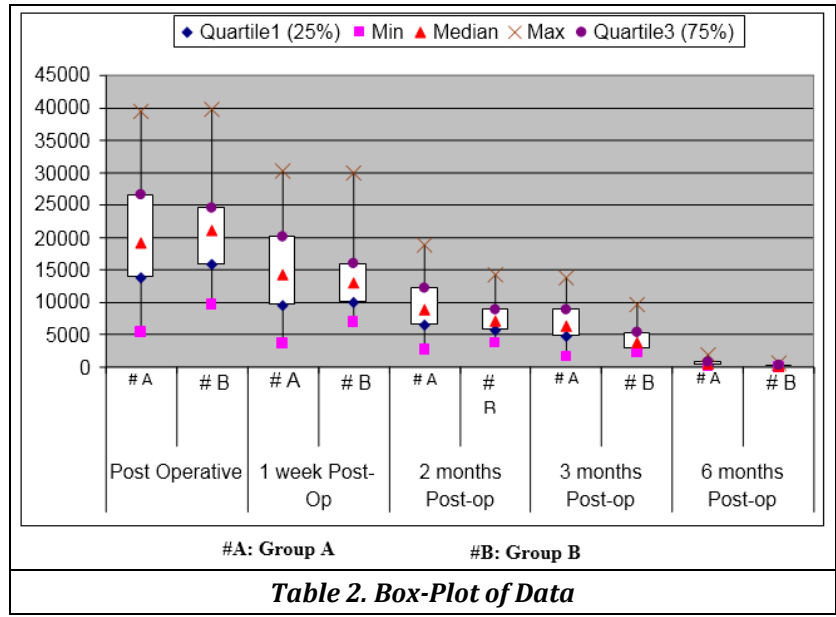

\begin{tabular}{|c|c|c|c|c|}
\hline $\begin{array}{c}\text { Parameter } \\
\text { Assessed }\end{array}$ & Absent (0) & Mild (1) & $\begin{array}{c}\text { Moderate } \\
\text { (2) }\end{array}$ & Severe (3) \\
\hline Pain & 39 & 10 & - & 1 \\
\hline Swelling & 42 & 4 & 3 & 1 \\
\hline Erythema & 49 & 1 & - & - \\
\hline $\begin{array}{c}\text { Wound } \\
\text { Dehiscence }\end{array}$ & 48 & - & - & 2 \\
\hline Pus Discharge & 48 & -- & - & 2 \\
\hline \multicolumn{7}{|c|}{ Table 3. Soft Tissue Evaluation for Group A (n=50) } \\
\hline
\end{tabular}

\begin{tabular}{|c|c|c|c|c|}
\hline $\begin{array}{c}\text { Parameter } \\
\text { Assessed }\end{array}$ & Absent (0) & Mild (1) & Moderate (2) & Severe (3) \\
\hline Pain & 46 & 2 & 1 & 1 \\
\hline Swelling & 47 & 2 & - & 1 \\
\hline Erythema & 49 & 1 & - & - \\
\hline $\begin{array}{c}\text { Wound } \\
\text { Dehiscence }\end{array}$ & 50 & - & - & - \\
\hline Pus Discharge & 49 & - & - & 1 \\
\hline \multicolumn{6}{|c|}{ Table 4. Soft Tissue Evaluation for Group B (n=50) } \\
\hline
\end{tabular}

\begin{tabular}{|c|c|c|c|c|c|c|}
\hline Group & $\mathbf{n}$ & Mean & $\begin{array}{c}\text { Std. } \\
\text { Dev. }\end{array}$ & $\begin{array}{c}\text { Mean } \\
\text { difference }\end{array}$ & t & $\begin{array}{c}\text { p- } \\
\text { Value }\end{array}$ \\
\hline A & 50 & 6.90 & 1.42 & 2.600 & 14.227 & $\begin{array}{c}<0.000 \\
1 *\end{array}$ \\
\hline B & 50 & 4.30 & 1.92 & Group A and Group B \\
\hline Table 5. Comparison of All the Healing Parameters Between \\
*denotes statistically significant
\end{tabular}

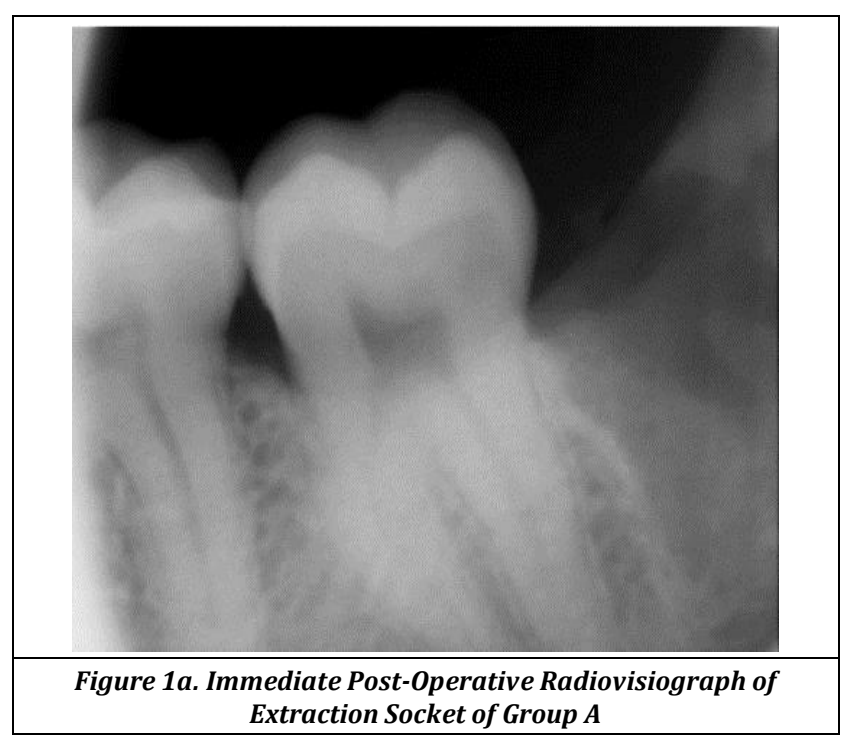

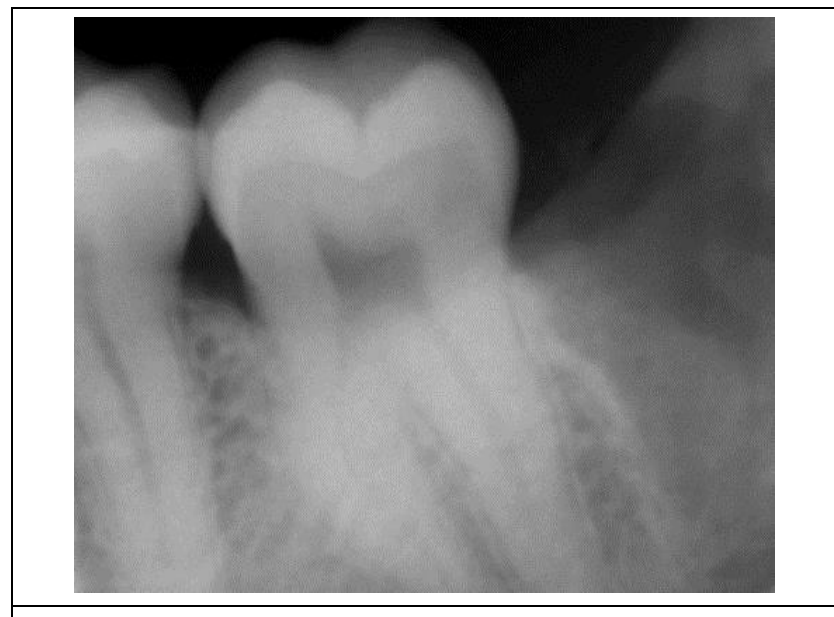

Figure 1b. $1^{\text {st }}$ Week Post-Operative Radiovisiograph of Extraction Socket of Group A
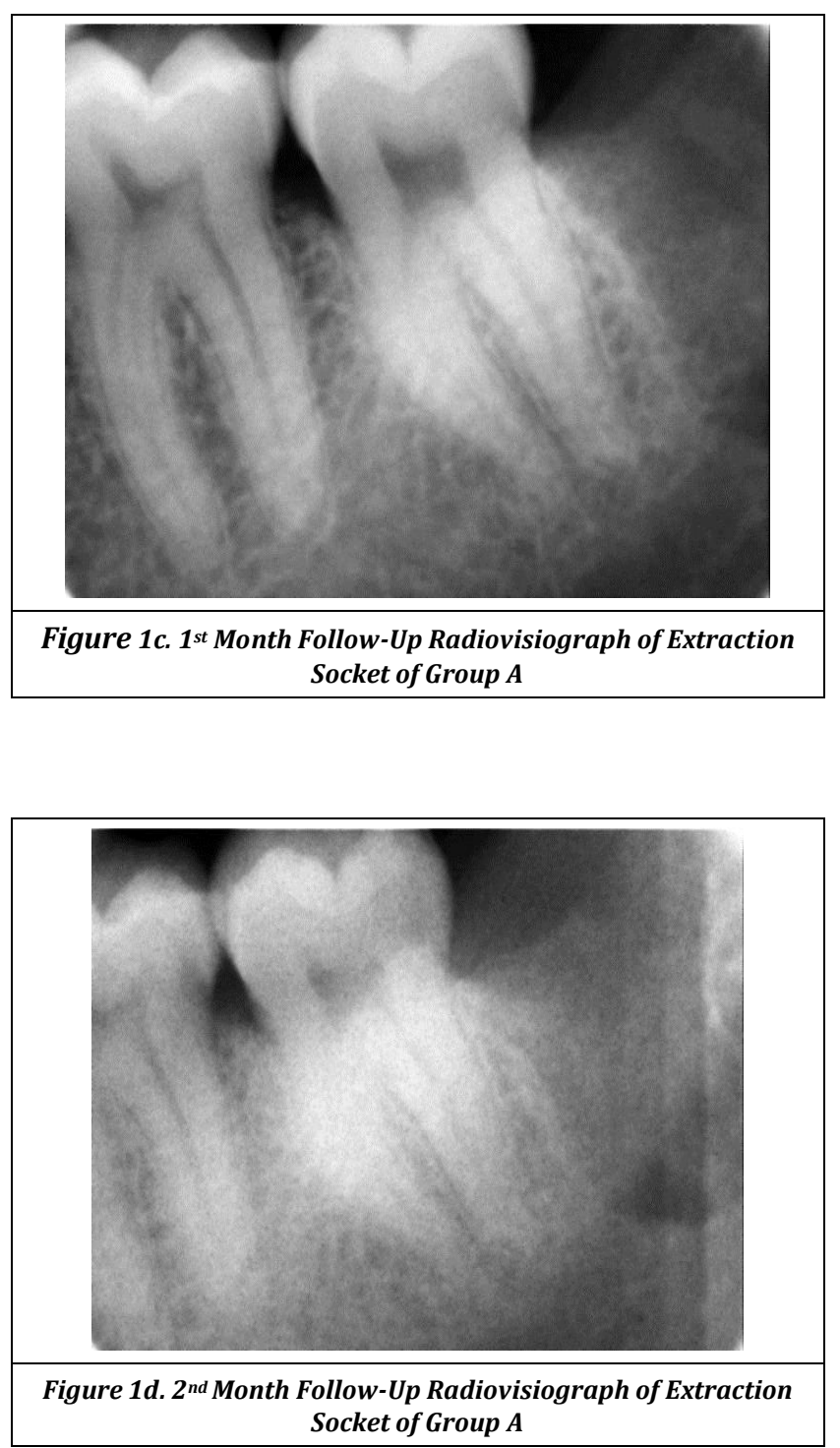

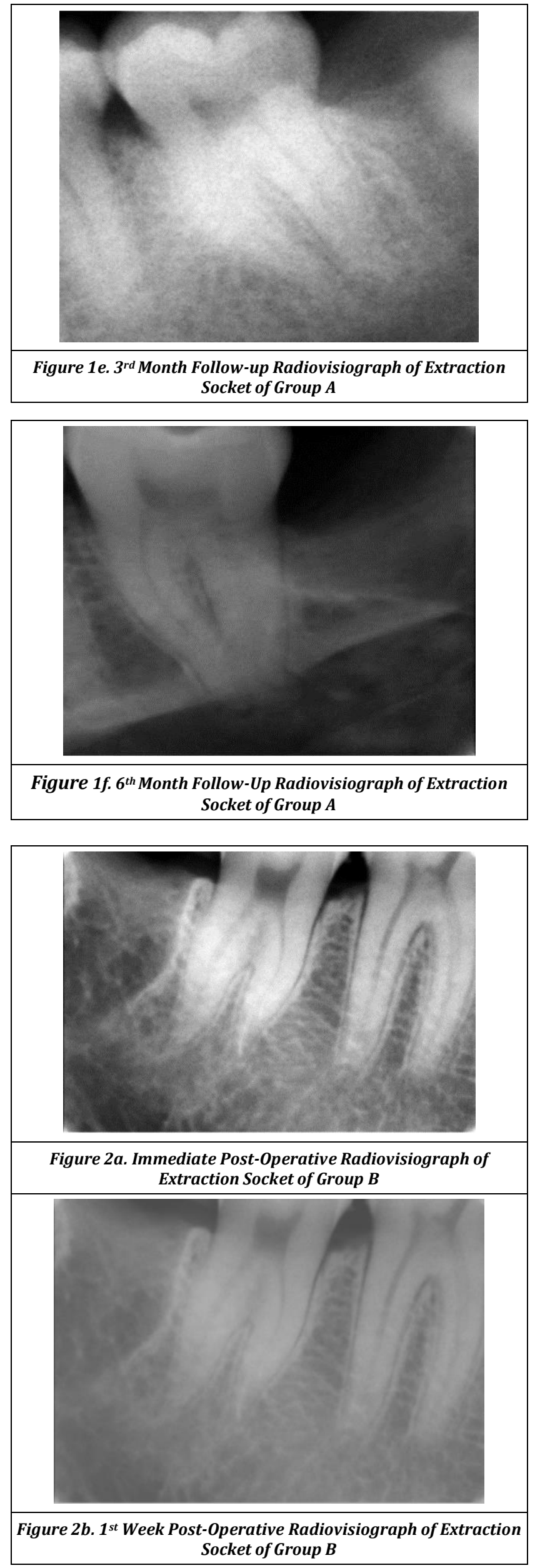

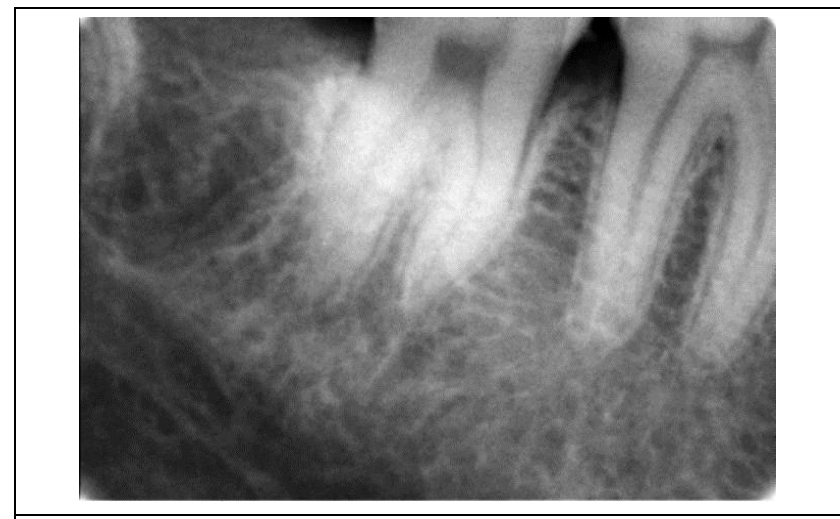

Figure 2c. $1^{\text {st }}$ Month Post-Operative Radiovisiograph of Extraction Socket of Group B
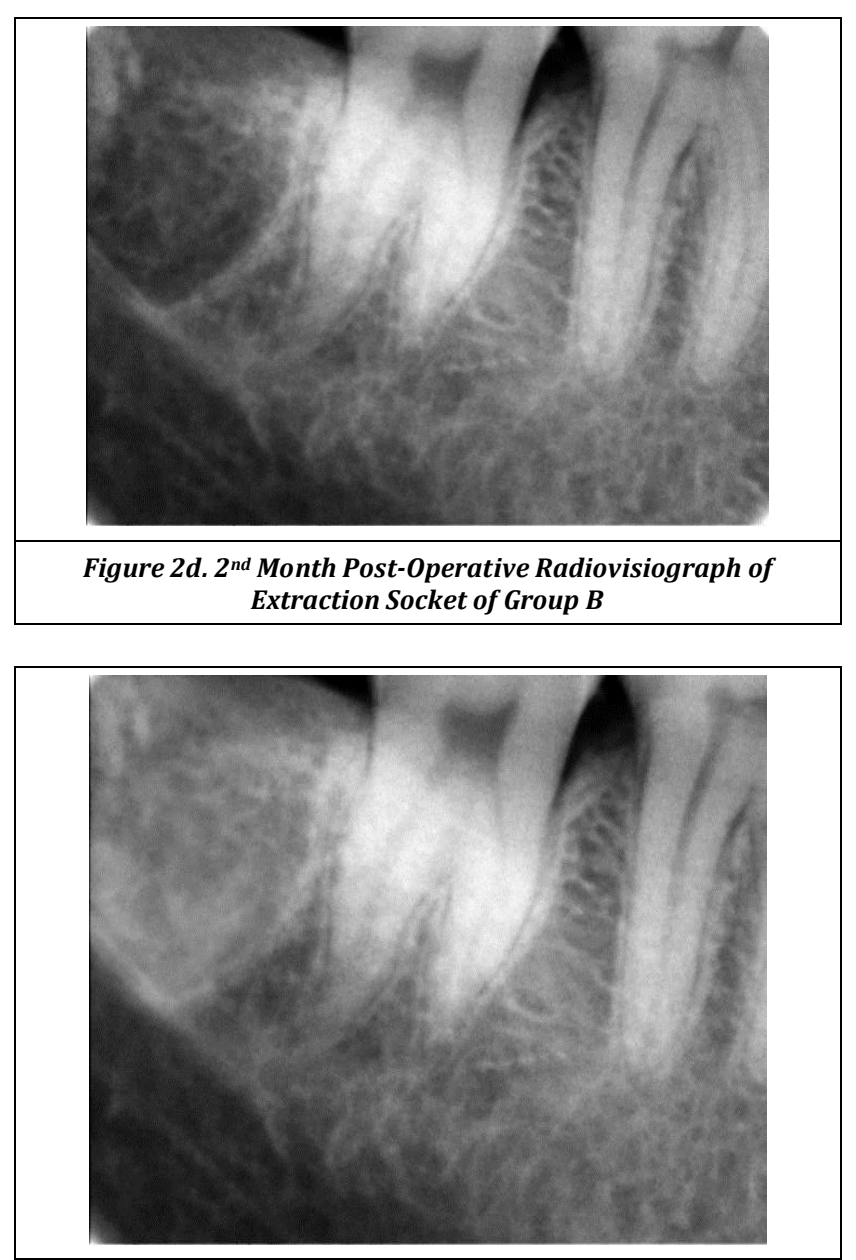

Figure 2e. $3^{\text {rd }}$ Month Operative Radiovisiograph of Extraction Socket of Group B

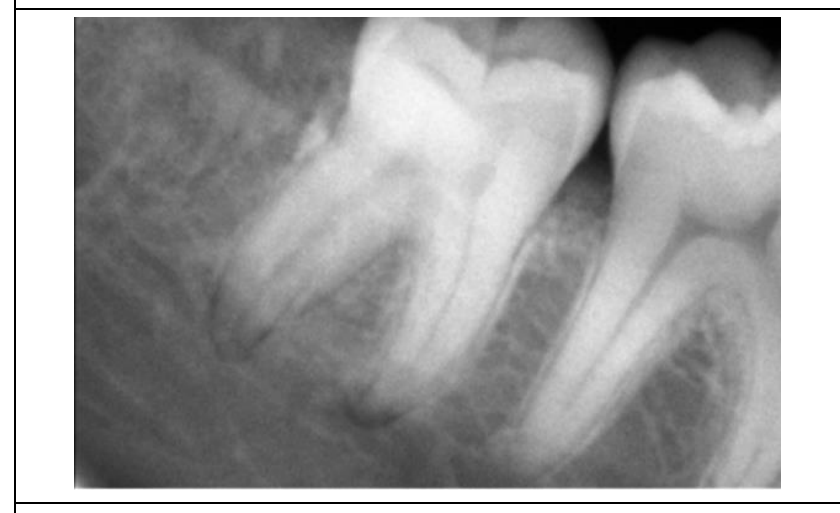

Figure 2f. $6^{\text {th }}$ Month Post-Operative Radiovisiograph of Extraction Socket of Group B 


\section{DISCUSSION}

The PRF, a blood derived product is bioactive surgical additive to promote wound healing stems from the use of fibrin adhesives ${ }^{2}$. Its chief advantages being easy preparation and no biochemical handling of blood, making it purely autologous.3,4

It is obtained by natural progressive polymerization represents a particularly homogeneous 3-dimensional organization, tightly coherent cytokines in the fibrin meshes (Intrinsic cytokines). ${ }^{7}$ This means an increased cytokine lifespan as they will be released and used only at the time of initial matrix remodelling and hence maintained in situ for a convenient period.8,9

PRF is not only a platelet concentrate but also an immune node able to stimulate defence mechanisms. It is even likely that the significant inflammatory regulation noted on surgical sites treated with PRF is the outcome of retro control effects from cytokines trapped in the fibrin network and released during the remodelling of this initial matrix. ${ }^{10}$

Angiogenesis, immunity, and epithelial cover are the 3 keys to healing and soft tissue maturation. The membranes of PRF are able to simultaneously support the development of these 3 phenomena. PRF can hence protect open wounds and accelerate healing. Furthermore, leukocytes contained contribute in healing of infected wounds.7,8

Metronidazole is a surgical adjuvant. This antibiotic from the nitro-5 imidazole family is often used orally or applied locally. It is a partially hydrophilic drug, which effectively inhibits anaerobic microorganisms and protozoan infections ${ }^{11}$ and when used with graft is proved to reduce early inflammatory reactions immediately post-operative. The presence of antibiotic limits the graft (PRF gel) contamination and protects early phases of bone regeneration from infection. 12

Incorporated into the graft Metronidazole protects against the systemic peri-operative contamination by anaerobic bacteria. But it can never replace strict aseptic protocols that need to be followed during the procedure and general antiseptic covering. This protocol is not an antibiotherapy: $2 \mathrm{ml}$ of $0.5 \%$ solution contains only $10 \mathrm{mg}$ metronidazole i.e., $1 / 40$ of a standard $400 \mathrm{mg}$ oral tab ${ }^{13}$. This is just enough to limit the contamination of the biomaterial and to protect early phase of bone construction from infection and related inflammatory reaction.

Clinical observation of one-week post-operative soft tissue healing in group A and Group B indicated better healing in patients receiving PRF gel with metronidazole than of those receiving only PRF. The patients also expressed less discomfort on the side of group B sockets in terms of pain and swelling.

Hard tissue evaluation radiographically showed an average decrease in defect size by $66.23 \%$ and $79.89 \%$ in Group B than $51.77 \%$ and $63.98 \%$ decrease in group A at two months and three months postoperative respectively. At six months, reduction in defect size in the group B was on an average by $98.46 \%$ in comparison to reduction by $95.31 \%$ in the group A.

The Advantages of PRF GEL Infused with Metronidazole are-

- Autologous over homologous.

- Convenience for patient with no visit to blood bank.

- Improves tissue healing.
- Increased rapid mineralization of collagen in bone repair and graft sites.

- Cytokines and growth factors are brought to the site.

- Formation of firm non friable clot.

- Jumpstarts the cascade of osteogenesis.

- Improves trabecular bone density.

- Provides early access to growth factors and bone morphogenetic proteins.

- Antibiotic incorporated provides localized benefits such as gel stabilization, improved healing and accelerated bone formation.

Although the exact mechanism as to why the infused antibiotic improves bone regeneration cannot be pin pointed, it could be stated from this study that the initial protection of the gel and its stabilization by the antibiotic improves its sustainability in the socket leading to faster and prolonged bone regeneration. However further studies in depth to the same are desirable.

\section{CONCLUSIONS}

Platelet rich fibrin gel with Metronidazole significantly increases bone regeneration (reduction in defect size) as implied by quick and comprehensive bone formation observed in the group B sockets. At every follow-up, a marked decrease in defect size was noticed in both group A and group B. The soft tissue healing around sockets of Group B was also found to be more effective. Therefore, amalgamating metronidazole into PRF gel provides simple economic solution to the unpredictable challenges of enhanced bone and tissue healing. It has been established beyond doubt with past researches that PRF augments bone regeneration and enhances physiologic bone healing. On the basis of our study we corroborate that providing an antibiotic infusion with the PRF not only stabilizes the gel and promotes initial healing but generates bony healing and regeneration at a greater pace. Further insight into the therapeutic arsenal of PRF and its unexplored properties is desirable. To summarise, the study establishes that PRF gel infused with Metronidazole is an apt adjuvant for improved post-operative healing and bone formation in small defects such as extraction sockets.

\section{REFERENCES}

[1] Shetty T, Rao G, Bhat P. Platelet Rich Fibrin (PRF) Gel as a medium for local drug delivery of Metronidazole. International Journal of Advances in Health Sciences 2014;1(3):113-22.

[2] Choukroun J, Diss A, Simonpieri A, et al. Platelet-rich fibrin (PRF): a second-generation platelet concentrate. Part V: histologic evaluations of PRF effects on bone allograft maturation in sinus lift. Oral Surg Oral Med Oral Pathol Oral Radiol Endod 2006;101(3):299-303.

[3] Dohan DM, Choukroun J, Diss A, et al. Platelet-rich fibrin (PRF): a second-generation platelet concentrate. Part III: leucocyte activation: a new feature for platelet concentrates? Oral Surg Oral Med Oral Pathol Oral Radiol Endod 2006;101(3):e51-e5. 
[4] Diss A, Dohan DM, Mouhyi J, et al. Osteotome sinus floor elevation using Choukroun's platelet-rich fibrin as grafting material: a 1-year prospective pilot study with microthreaded implants. Oral Surg Oral Med Oral Pathol Oral Radiol Endod 2008;105(5):572-9.

[5] Toffler M, Toscano N, Holtzclaw D, et al. Introducing Choukron's platelet rich fibrin to the reconstructive surgery milieu. The Journal of Implant and Advanced Clinical Dentistry 2009;1:21-31.

[6] Sunitha RV, Munirathnam NE. Platelet-rich fibrin: Evolution of a second-generation platelet concentrate. Indian Journal of Dental Research 2008;19(1):42-6.

[7] Dohan DM, Choukroun J, Diss A, et al. Platelet-rich fibrin (PRF): a second-generation platelet concentrate. Part I: technological concepts and evolution. Oral Surg Oral Med Oral Pathol Oral Radiol Endod 2006;101(3):e37-44.

[8] Chiapasco M, Rossi A, Motta JJ, et al. Spontaneous bone regeneration after enucleation of large mandibular cysts: A radiographic computed analysis of 27 consecutive cases. J Oral Maxillofac Surg 2000;58(9):942-9.
[9] Cieslik-Bielecka A, Bielecki T, Gazdzik TS, et al. Improved treatment of mandibular odontogenic cysts with platelet-rich gel. Oral Surg Oral Med Oral Pathol Oral Radiol Endod 2008;105(4):423-9.

[10] Shifrovitch Y, Binderman I, Bahar H, et al. Metronidazole-loaded bioabsorbable films as local antibacterial treatment of infected periodontal pockets. J Periodontol 2009;80(2):331-7.

[11] Simonpieri A, Del Corso M, Sammartino G, et al. The relevance of Choukroun's platelet rich fibrin and metronidazole during complex maxillary rehabilitations using bone allograft. Part 1: a new grafting protocol. Implant Dentistry 2009;18(2):10211.

[12] Lo"fmark S, Edlund C, Nord CE. Metronidazole is still the drug of choice for treatment of anaerobic infections. Clinical Infectious Diseases 2010;50(Suppl 1):S16-S23.

[13] Hearnden V, Sankar V, Hull K, et al. New developments and opportunities in oral mucosal drug delivery for local and systemic disease. Advanced Drug Delivery Reviews 2012;64(1):16-28. 